\title{
microphthalmia, a critical factor in melanocyte development, defines a discrete transcription factor family
}

\author{
Timothy J. Hemesath, ${ }^{1}$ Eirikur Steingrímsson, ${ }^{2}$ Gaël McGill, ${ }^{1}$ Michael J. Hansen, ${ }^{1}$ James Vaught, ${ }^{1}$ \\ Colin A. Hodgkinson, ${ }^{3}$ Heinz Arnheiter, ${ }^{3}$ Neal G. Copeland, ${ }^{2}$ Nancy A. Jenkins, ${ }^{2}$ \\ and David E. Fisher ${ }^{1,4}$ \\ ${ }^{1}$ Division of Pediatric Hematology/Oncology, Dana Farber Cancer Institute and Children's Hospital, Harvard Medical \\ School, Boston, Massachusetts 02115 USA; ${ }^{2}$ Mammalian Genetics Laboratory, ABL-Basic Research Program, National \\ Cancer Institute-Frederick Cancer Research and Development Center, Frederick, Maryland 21702 USA; ${ }^{3}$ Laboratory of Viral \\ and Molecular Pathogenesis, National Institute of Neurological Disorders and Stroke, National Institutes of Health, \\ Bethesda, Maryland 20892 USA
}

The microphthalmia (mi) gene appears essential for pigment cell development and/or survival, based on its mutation in mi mice. It has also been linked to the human disorder Waardenburg Syndrome. The mi gene was recently cloned and predicts a basic/helix-loop-helix/leucine zipper (b-HLH-ZIP) factor with tissue-restricted expression. Here, we show that Mi protein binds DNA as a homo- or heterodimer with TFEB, TFE3, or TFEC, together constituting a new MiT family. Mi can also activate transcription through recognition of the $M$ box, a highly conserved pigmentation gene promoter element, and may thereby determine tissue-specific expression of pigmentation enzymes. Six mi mutations shown recently to cluster in the b-HLH-ZIP region produce surprising and instructive effects on DNA recognition and oligomerization. An alternatively spliced exon located outside of the b-HLH-ZIP region is shown to significantly modulate DNA recognition by the basic domain. These findings suggest that Mi's critical roles in melanocyte survival and pigmentation are mediated by MiT family interactions and transcriptional activities.

[Key Words: microphthalmia, dimerization; DNA binding; M box; b-HLH-ZIP]

Received August 23, 1994; accepted in revised form October 11, 1994.

A striking inheritable disorder of development in the mouse is microphthalmia ( $\mathrm{mi}$ ), a syndrome first recognized $>50$ years ago as a coat color mutation (Hertwig 1942). The human mi gene has also been linked compellingly to the human pigment cell disorder Waardenburg Syndrome (Hughes et al. 1994). Mutations at the mouse mi locus result in pigment cell defects in the skin (producing white spotting), eyes (producing small eyes), and inner ears (resulting in deafness). Mast cell defects have also been recognized for certain $m i$ alleles, a pattern resembling the melanocyte/mast cell pattern of Sl/kit-defective mice and suggesting a connection between these factors in signaling (Dubreuil et al. 1991; Ebi et al. 1992). Bone resorption and other neural crest or neuroepithelial defects have also been observed for certain mi alleles (for review, see Green 1989), suggesting that Mi protein may function in part through oligomeric interactions with other factors.

The devastating consequences of mi mutations on melanocyte development suggest that $\mathrm{Mi}$ is a key regulator

${ }^{4}$ Corresponding author. of melanocyte growth or survival. The $m i$ gene was cloned recently and shown to predict a basic/helixloop-helix/leucine zipper (b-HLH-ZIP) factor (Hodgkinson et al. 1993; Hughes et al. 1993; Tachibana et al. 1994). Mammalian b-HLH-ZIP factors and the related b-HLH group contain several important regulators of cell proliferation and development such as $\mathrm{Myc} / \mathrm{Max}$ (Blackwood and Eisenman 1991; Prendergast et al. 1991) and MyoD-related factors (for review, see Olson 1990, and references therein; Weintraub 1994). Given the effects of mi mutations on melanocyte biology, mi may regulate comparable pathways in melanocytes. Although a significant number of b-HLH-ZIP factors are known, biological activities are clear for only a few, primarily Myc and its related partners (see Prendergast and Ziff 1992; Ayer and Eisenman 1993; Zervos 1993). Only very few candidate target genes have been identified so far that are regulated by these factors. The striking biological consequences of mi mutations suggest a major role in melanocyte development and even point to specific candidate target genes.

Melanocytes represent a neural crest-derived lineage whose pigmentation function is easily assessed because 
melanocytes are not critical to survival of the whole animal. A great deal has been learned about pigmentation enzymes and their regulation through study, for example, of albino (tyrosinase) mutants (for review, see Halaban and Moellmann 1993). Determination of regulatory elements critical for pigmentation have revealed an 11bp sequence known as the $\mathrm{M}$ box containing the core element CATGTG, which is highly conserved in the promoters of the three major pigmentation enzyme genes tyrosinase, and tyrosinase-related proteins 1 and 2 (Shibahara et al. 1991; Lowings et al. 1992; Yavuzer and Goding 1994). The presence of tissue-specific transcription factors capable of interacting with and transcriptionally activating elements such as this may shed light on the regulation of pigmentation and perhaps other melanocyte-specific functions.

The opportunity to examine structure/function relationships for transcription factor mutations coordinately in vitro and in mice has rarely been possible. The multitude of mi mouse mutants provides a unique opportunity to examine biochemical consequences of biologically important b-HLH-ZIP mutations. The b-HLHZIP family contains a short $\sim 20$-amino-acid basic domain rich in basic amino acids that makes sequencespecific DNA contacts. Carboxy-terminal to it is the HLH-ZIP containing two amphipathic helices separated by a flexible loop and a carboxy-terminal leucine zipper. The HLH-ZIP mediates dimeric interactions necessary for DNA binding (Ferré-D'Amaré et al. 1993). Restricted heterodimerization plays a major role in regulating developmental programs ranging from inhibition of myogenesis by the HLH protein Id (Benezra et al. 1990) or morphogenesis by extramachrocaete (Ellis et al. 1990; Garrel and Modolell 1990) to cooperation in cellular transformation by Myc/Max (Blackwood and Eisenman 1991; Prendergast et al. 1991; Kato et al. 1992; Amati et al. 1993). The ability to group these factors into families, based on dimerization specificities, provides a useful handle for analysis of their biological roles.

Most b-HLH-ZIP proteins recognize the hexamer core sequence CACGTG or the related sequence CATGTG, whereas AP-4 (Hu et al. 1990) and most b-HLH proteins recognize CAGNTG hexamers. A hexamer containing the CATGTG sequence is present in the mouse immunoglobulin heavy chain enhancer and was used to isolate and characterize the transcription factor TFE3 (Beckmann et al. 1990; Roman et al. 1992). Although most b-HLH-ZIP factors interact avidly with cognate targets, it has been difficult to elucidate tissue-specific activities, in part because most of these factors are expressed ubiquitously. In this regard, mi, which is tissue restricted, is an attractive candidate as an M-box activator and regulator of pigmentation gene expression.

The studies described here identify Mi's DNA-binding activity and its ability to form stable DNA-binding heterodimers with TFEB, TFE3, and TFEC, three other b-HLH-ZIP factors. Collectively, these four proteins comprise a distinct family that likely modulates the biological activity of $\mathrm{Mi}$ through hetero-oligomer formation. The biological importance of Mi's protein-protein and protein-DNA interactions have been revealed through a characterization of the proteins encoded by seven mutant mi mouse alleles (Steingrímsson et al. 1994). These mutations cluster within or near the b-HLH-ZIP motif of $m i$ and display striking effects on heterodimerization and DNA binding that largely explain the unique severity and inheritance patterns of the different mi mouse strains. Novel structural features of b-HLH-ZIP biochemistry have also been revealed, such as the surprising ability of an alternative exon outside of the basic domain to modulate b-HLH-ZIP-dependent DNA recognition. Finally, Mi was shown to transcriptionally activate a reporter driven by the pigmentation promoter M-box element, suggesting that this family of factors plays a central role in the tissue-specific development of melanocytes.

\section{Results}

\section{$D N A$ recognition by $\mathrm{Mi}$}

The Mi protein produces a gel shift complex (Fig. 1) with DNA containing the CACGTG hexanucleotide derived from adenovirus major late promoter (MLP). Several deletions were made to determine the protein domains required for DNA binding (Fig. 1A). It was possible to truncate from the amino terminus to the beginning of the basic domain and from the carboxyl terminus to the end of the leucine zipper domain without loss of DNA binding (Fig. 1B, lanes 2-4). Further deletion from the carboxyl terminus removed part of the leucine zipper and abolished DNA binding (Fig. 1B, lane 5). Therefore, the leucine zipper was essential for stable complex formation.

Sequence specificity of DNA recognition was verified by competition analysis using both CACGTG (Fig. 1C) and CATGTG (Fig. 1D) probes. In each case, a double point mutant (GAGGTG) failed to compete the specific complex at concentrations effectively competed by unlabeled CACGTG competitor.

\section{Mi is a member of a discrete family of $b-H L H-Z I P$ factors}

Stoichiometry of protein to DNA in the bound complexes was examined by mixing full-length $\mathrm{Mi}$ protein with the isolated b-HLH-ZIP region (Fig. 2, lanes 2 and 3 , respectively). A single new intermediate mobility gel shift complex was observed (Fig. 2, lane 4). Overexposure failed to reveal additional intermediate complexes, suggesting that the protein-DNA stoichiometry is $2: 1$.

Experiments were also undertaken to determine whether $\mathrm{Mi}$ is capable of forming DNA-binding heterodimers with several other b-HLH-ZIP proteins. Only three proteins, TFEB, TFE3, and TFEC, were found to form intermediate mobility complexes with Mi (Fig. 2, lanes 5-13). In these mixing experiments TFE3 (but not Mi) preferentially heterodimerizes, probably reflecting different kinetics from $\mathrm{Mi}$. In contrast, no heterodimers 

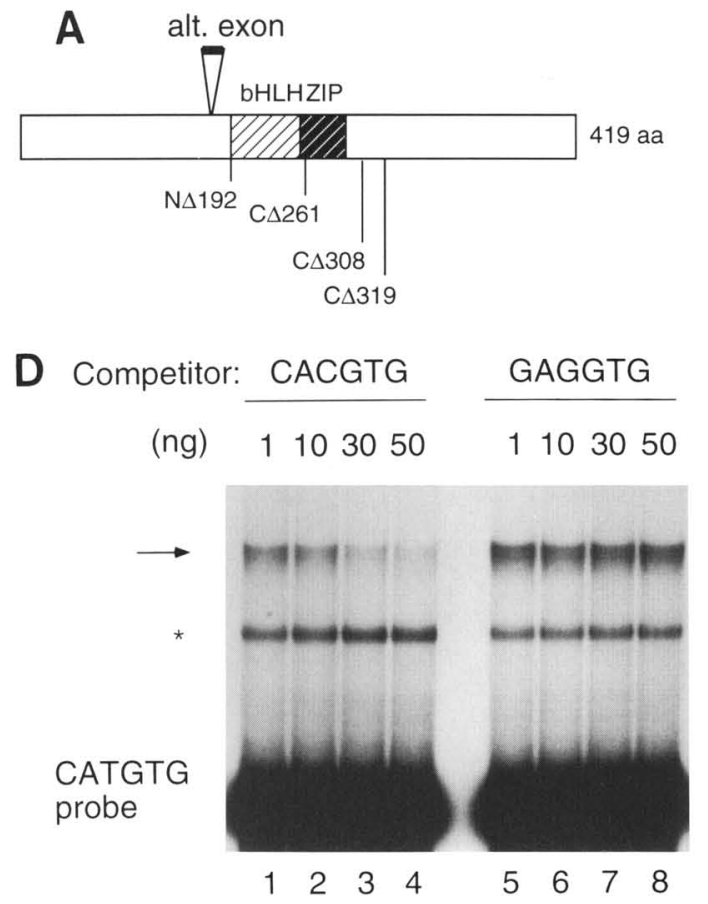
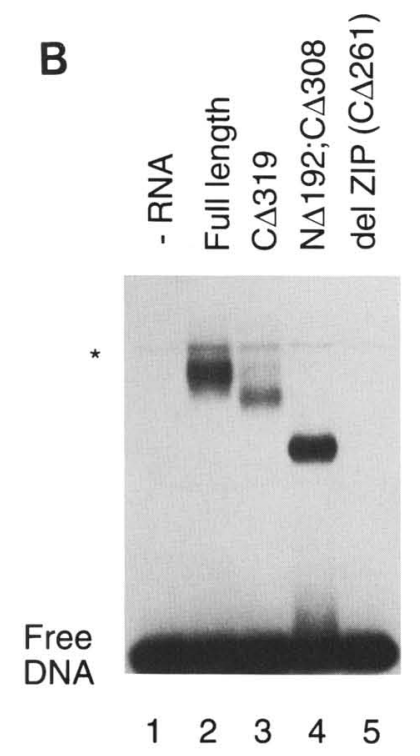
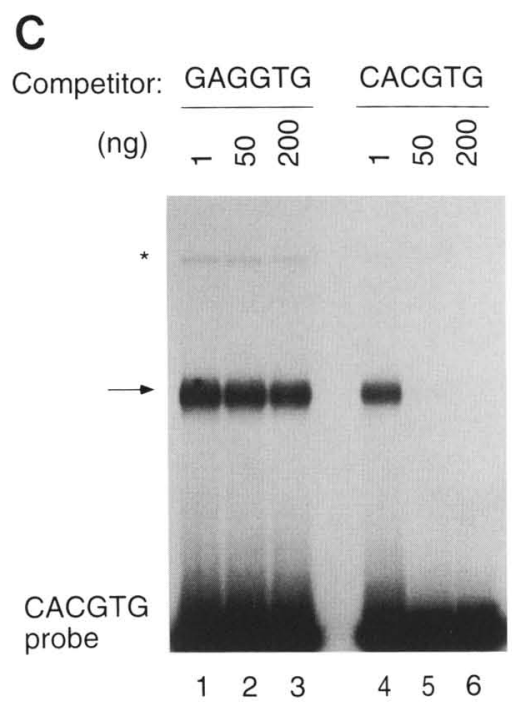

Figure 1. mi gene and deletion analysis. $\{A\}$ Schematic representation of the Mi protein. Hatched areas depict basic helix-loop-helix, and leucine zipper domains (b-HLH-ZIP). Positions of the various amino-terminal and carboxy-terminal deletions are indicated using numbering based on the melanocyte form of Mi that contains 419 amino acids (Hodgkinson et al. 1993; Steingrímsson et al. 1994). (B) DNA binding by Mi. Radiolabeled DNA containing the core hexanucleotide CACGTG was used in gel shift analysis. Proteins were derived from in vitro translation using reticulocyte lysate and were either full length or truncated as indicated. Endogenous reticulocyte DNA binding is indicated by an asterisk (*). (- RNA) Reticulocyte lysate unprogrammed by exogenous RNA. (C) Competition for CACGTG probe. Mi protein containing an intact b-HLH-ZIP region (truncation N $\Delta 192 ; \mathrm{C} \Delta 308$ ) was tested for DNA binding to radiolabeled CACGTG probe. Unlabeled competitor DNA fragments of identical size were added as indicated in units of nanograms. Core sequences of the competitors are shown. $\left(^{*}\right)$ A background reticulocyte activity; $(\rightarrow \mid$ Mi specific activity. $(D)$ Competition for CATGTG probe. Purified recombinant Mi protein was bound to radiolabeled $\mu$ E3 probe DNA in the presence of unlabeled competitor DNAs as indicated. $(\rightarrow)$ The Mi specific activity; $(*)$ a contaminating activity present in the probe.

were observed upon mixing Mi with E47S (Fig. 2, lanes 14-16), Max, Myc, upstream stimulatory factor (USF), or several non-HLH-containing transcription factors (data not shown). Therefore, of the known and tested candidate partners, $\mathrm{Mi}$ appears to be capable of forming stable DNA-binding heterodimers with only TFEB, TFEC, and TFE3. With the additional observation that TFEB and TFEC form stable heterodimers (Fig. 2), all combinations of these four proteins have now been shown to heterodimerize with one another but not with any other known b-HLH-ZIP proteins (Fig. 2; Fisher et al. 1991; Zhao et al. 1993), indicating that they constitute a discrete group of interactive proteins, which we refer to as the MiT family.

\section{Mutant alleles affect MiT interactions}

Recent molecular genetic studies of Steingrímsson et al. (1994) suggest that dominant-negative Mi mutations are dominantly inherited while regulatory mutations or mutations that prevent or reduce Mi protein dimerization are recessively inherited. To examine this possibility, mutant proteins corresponding to the seven mi mutations characterized by Steingrímsson et al. (1994) were produced and tested directly for their ability to bind DNA as homodimers or as heterodimers with TFE3. Identical results were obtained when heterodimerization was tested with wild-type Mi, TFEB, or TFEC /data not shown). The seven mutations and their properties are summarized in Table 1.

When tested for homodimeric DNA binding, all three semidominant and two recessive mutant proteins failed to bind DNA (Fig. 3A, lanes 3-8). Only the helix $1 \mathrm{mu}-$ tant D222N (mivit) mutant protein, which is inherited recessively, appeared to bind DNA normally. Quantitative affinity measurements revealed $\mathrm{mi}^{\mathrm{vit}}$ to bind with a $K_{\mathrm{d}}$ only $6 \%$ greater than that of wild-type $\mathrm{Mi}$ /using forms containing the 6-residue alternative insert), a difference within the $10 \%$ standard error of our measurements (data not shown). When mixed with TFE3, mivit was the only mutant protein able to produce a heterodimeric complex with TFE3 (Fig. 3A, lanes 10-16).

Examination of heterodimer mixing experiments using the mutant $\mathrm{Mi}$ proteins (Fig. $3 \mathrm{~A}$ ) revealed a striking loss of TFE 3 homodimer activity in many reactions. Addition of $\mathrm{mi}, \mathrm{Mi}^{\text {or }}, \mathrm{Mi}^{\mathrm{wh}}$, or $\mathrm{mi}^{\mathrm{ew}}$ proteins essentially ablated TFE3 homodimeric DNA-binding activity (Fig. $3 \mathrm{~A}$, lanes $12,13,15,16)$. In contrast, the recessive allele 


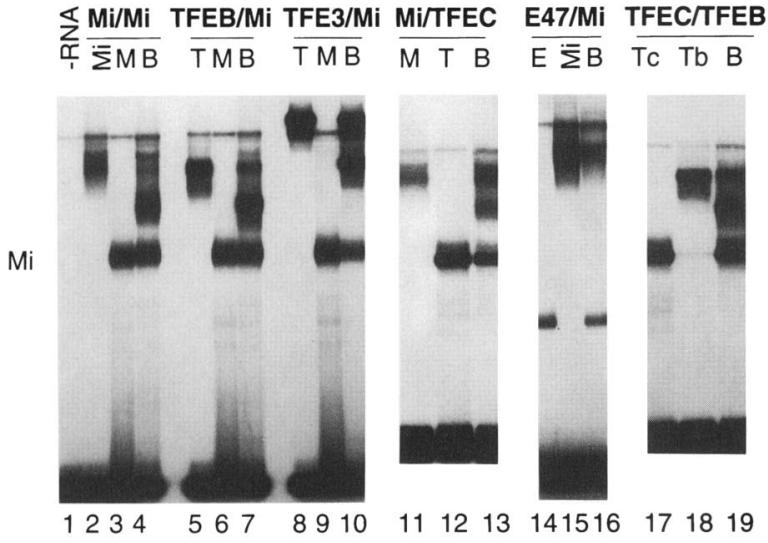

Figure 2. Mi forms stable heterodimers with TFEB, TFE3, and TFEC. Full-length and truncated forms of various b-HLHZIP proteins were translated separately in vitro and equivalent volumes were mixed (post-translationally) prior to the addition of radiolabeled CACGTG probe. (M) The Mi truncation $\mathrm{N} \Delta 192 ; \mathrm{C} \Delta 308$; (Mi) full-length Mi protein; (B) both proteins mixed together; (T) TFEB, TFE3, or TFEC as indicated; (Tc) $\mathrm{TFEC}_{i}(\mathrm{~Tb}) \mathrm{TFEB}$. The Mi used in lanes 3-10 encompasses the b-HLH-ZIP region; the Mi used in lanes 2 and 11-16 is full length. The fragment of TFEB used contains all but the first 265 amino acids (TFEB-A $\Delta 265$; Fisher et al. 1991). TFE3 is fulllength (Beckmann et al. 1990). The TFEC fragment contains the isolated b-HLH-ZIP region (NA99; C $\Delta 204)$. E47S is a truncation of E47 that includes the b-HLH region (Mürre et al. 1989).

$\mathrm{mi}^{\text {ce }}$ contains a stop codon that removes the leucine zipper and did not affect TFE3-binding activity (Fig. 3A, lane 11). All three semidominant alleles contain basic domain mutations, failed to bind as homodimers, and additionally suppressed DNA binding by TFE3 in an apparently dominant-negative fashion.

Surprisingly, of the three recessive mutant proteins, $\mathrm{mi}^{\text {vit }}$ bound DNA indistinguishably from wild-type protein despite its helix 1 mutation (and the striking phenotype of $\mathrm{mi}^{\text {vit }}$ mice) (Fig. 3A, lanes 6,14), suggesting that this mutation might disrupt a function other than DNA binding. The recessive allele, $\mathrm{mi}^{c e}$, contains a stop codon at the beginning of the leucine zipper, failed to bind DNA, and was also incapable of suppressing the DNA-binding activity of TFE3 (Fig. 3A, lanes 3,11) behaving "recessively" in vitro. A third recessive mutation, $\mathrm{mi}^{e w}$, contains a 25 -amino-acid deletion that removes the amino-terminal half of the basic region but does not involve the HLH-ZIP. This mutant failed to bind DNA as a homodimer and also suppressed the DNA-binding activity of TFE3 (Fig. 3A, lanes 8,16). As a basic domain deletion, this in vitro behavior was expected for $\mathrm{mi}^{\mathrm{ew}}$. Its recessive inheritance is surprising, however. Importantly, this discrepancy between the biochemical behavior of the $\mathrm{mi}^{\mathrm{ew}}$ protein and the genetic behavior of the $\mathrm{mi}^{\mathrm{ew}}$ allele suggests that these deleted 25 amino acids carry out a second function (aside from DNA binding).

To verify that the TFE3 suppression seen by proteins encoded by the semidominant alleles occurred through protein-protein interactions, coimmunoprecipitations were performed using ${ }^{35} \mathrm{~S}$-labeled mutant $\mathrm{Mi}$ proteins, unlabeled recombinant TFEB, and a TFEB-specific antibody. Antibody specificity was verified by supershift of a TFEB/DNA complex but failure to supershift Mi or other b-HLH-ZIP proteins (data not shown). Specificity was indicated further by the dependence for TFEB in the coimmunoprecipitations (Fig. 3B, lanes 1,2) as well as the dependence of antibody (data not shown). The labeled Mi protein migrates as a doublet of $\sim 15 \mathrm{Kd}$. TFEBspecific antibodies coimmunoprecipitated wild-type $\mathrm{Mi}$, the three semidominant proteins $\mathrm{mi}, \mathrm{Mi}^{\text {or }}$, and $\mathrm{Mi}^{\text {wh }}$, as well as the recessive protein $\mathrm{mi}^{\text {vit }}$ (Fig. 3B, lanes 2-6), consistent with a dominant-negative inhibition of DNA binding by the products of the semidominant alleles. A similar coimmunoprecipitation pattern was also observed for $\mathrm{mi}^{\mathrm{ew}}$ (data not shown). The zipperless recessive protein $\mathrm{mi}^{\mathrm{ce}}$ did not efficiently coprecipitate (Fig. 3B, lane 7), although a weak signal was observed, possibly reflecting a propensity to form $\mathrm{HLH}$-mediated tetramers in the absence of DNA (Fisher et al. 1991; Anthony-Cahill et al. 1992; Farmer et al. 1992; Fairman et al. 1993).

\section{Alternative splice affects basic domain function}

The mi message exists in splice forms either encoding or lacking 6 amino acids just amino-terminal to the basic domain (Hodgkinson et al. 1993). The $\mathrm{mi}^{s p}$ mutation affects the polypyrimidine tract of the splice acceptor and precludes formation of $\mathrm{Mi}$ protein containing the 6-amino-acid insert (Steingrímsson et al. 1994). These mice produce normal pigment but exhibit a measurable decrease in the pigmentation enzyme tyrosinase within skin (Wolfe and Coleman 1964). Despite the subtlety of its homozygous phenotype, the $m i^{s p}$ allele enhances the effective phenotype of semidominant $m i$ alleles in a compound heterozygote (Wolfe and Coleman 1964). To examine biochemical relevance of this alternative splice, wild-type Mi proteins with and without the 6-aminoacid insert were examined (Fig. 4A, lanes 2,3). Although the two proteins bound DNA similarly, quantitative measurements revealed that the splice form containing the insert bound with $20 \%$ higher affinity than the form lacking the insert $\mid K_{\mathrm{d}}=290$ and $349 \mu \mathrm{M}$, respectively, in presence of poly $[\mathrm{d}(\mathrm{I}-\mathrm{C})]$. No large effect was observed for the alternative 6-amino-acid insert on heterodimeric binding of wild-type $\mathrm{Mi}$ with TFE3 (Fig. 4A, lanes 4-6).

Surprisingly, however, the presence of the 6-aminoacid insert had a profound effect on DNA binding of the basic domain mutant $\mathrm{I} 212 \mathrm{~N}\left(\mathrm{Mi}^{\mathrm{wh}}\right)$, the allele that displays interallelic complementation. As shown in Figure $4 \mathrm{~B}$, presence of the insert restored heterodimeric DNA binding by $\mathrm{Mi}^{\text {wh }}$ with a wild-type partner (Fig. 4B, lanes $1-4,9,11)$. In contrast, presence of the upstream insert did not restore heterodimeric DNA binding for a different basic region mutant (mi), indicating the specificity of this effect for $\mathrm{Mi}^{\mathrm{wh}}$ (Fig. 4B, lanes 5-7,10). Thus, presence of the upstream insert restored DNA binding to the $\mathrm{Mi}^{\text {wh }}$ protein if the heterodimer partner was wild type, 
Table 1. Microphthalmia mutant alleles

\begin{tabular}{|c|c|c|c|c|c|c|}
\hline & \multirow[b]{2}{*}{ Symbol } & \multirow[b]{2}{*}{ Mutation $^{a}$} & \multirow[b]{2}{*}{ Description } & \multicolumn{3}{|c|}{ DNA binding } \\
\hline & & & & homo- & hetero ${ }^{-b}$ & dom-neg \\
\hline \multicolumn{7}{|l|}{ Semidominant } \\
\hline microphthalmia & $m i$ & $\operatorname{del} \mathrm{R} 217^{\mathrm{d}}$ & deletion within basic domain & no & no & yes \\
\hline oak ridge & $M i^{\text {or }}$ & $\mathrm{R} 216 \mathrm{~K}$ & basic domain mutation (facing DNA) & no & no & yes \\
\hline white & $M i^{\text {wh }}$ & $\mathrm{I} 212 \mathrm{~N}$ & basic domain mutation (away from DNA) & no & yes $^{e}$ & yes $^{f}$ \\
\hline \multicolumn{7}{|l|}{ Recessive } \\
\hline cloudy eyed & $m i^{c e}$ & R263 STOP & deletes leucine zipper and carboxyl terminus & no & no & no \\
\hline eyeless white & $m i^{e w}$ & del A187-I212 & deletion into basic domain & no & no & yes \\
\hline vitiligo & $m i^{\text {vit }}$ & $\mathrm{D} 222 \mathrm{~N}$ & helix 1 mutation & yes & yes & no \\
\hline \multicolumn{7}{|l|}{ Enhancing } \\
\hline spotted & $m i^{s p}$ & del $186-191$ & loss of alternative 6-amino-acid exon & yes & yes & no \\
\hline $\begin{array}{l}\text { Interallelic complementation } \\
\text { white }\end{array}$ & $M i^{w h}$ & I212N & basic domain mutation (away from DNA) & no & yes $^{e}$ & yes $^{f}$ \\
\hline
\end{tabular}

aSteingrímsson et al. (1994).

bHeterodimeric DNA binding tested with wild-type binding partners (TFE3 and Mi).

'Dominant-negative effects tested through inhibition of homodimeric wild-type protein in same reaction.

d The mi allele deletes an Arg codon among a cluster of four in the basic domain. It is unclear which one has been deleted.

${ }^{\mathrm{e}} \mathrm{Mi} \mathrm{i}^{\mathrm{wh}}$ mutant protein can bind as heterodimer with wild type only in presence of the 6-amino-acid upstream insert and suppresses (dom-neg) only in absence of insert.

${ }^{\mathrm{f}} \mathrm{Mi}{ }^{\mathrm{wh}}$ mutant protein is dominant negative only in the absence of the 6-amino-acid upstream insert.

suggesting that this 6-amino-acid insert acts to stabilize the basic domain/DNA complex. Interestingly, the I212N mutation in the $\mathrm{Mi}^{\text {wh }}$ protein is the only basic region mutant predicted to face away from DNA in the basic domain $\alpha$-helix, on the solvent-exposed face (FerréD'Amaré et al. 1993; Fisher et al. 1993; Steingrímsson et al. 1994). The restoration of DNA binding for $\mathrm{Mi}^{\text {wh }}$ may account for the interallelic complementation characteristic of this allele.

\section{Mi overexpression transcriptionally activates an $M$ box-driven reporter in fibroblasts}

We have tested the ability of $m i$ to activate transcription of a reporter driven by the $\mathrm{M}$-box pigmentation gene promoter element (Shibahara et al. 1991; Lowings et al. 1992; Yavuzer and Goding 1994/ because of our demonstration that $\mathrm{Mi}$ is capable of binding its CATGTG core sequence in vitro (Fig. 1D). Cotransfection of $\mathrm{mi}$ and the $\mathrm{M}$-box reporter into NIH-3T3 cells resulted in Mi-dependent activation of the luciferase gene to levels $>13$-fold above controls (Fig. 5). Stimulation of the luciferase activity was dependent on both the presence of the M-box element in the reporter construct and on the cotransfection of mi. Although identical to the immunoglobulin enhancer element $\mu \mathrm{E} 3$ element at its core (CATGTG), the $M$ box differs in flanking positions, which are conserved from mouse to human in the three pigmentation enzyme genes tyrosinase, and tyrosinase-related proteins 1 and 2. Recognition of M-box elements by Mi may constitute a critical component in the elaboration of melanocyte-specific gene expression.

\section{Discussion}

The experiments presented here demonstrate that the Mi protein is a transcription factor that forms homo- and heterodimeric DNA-binding complexes within a small family of proteins and whose complexity of allelic interactions may be largely explained by these features. Biochemical analysis of $\mathrm{Mi}$ demonstrated its capacity to specifically recognize the DNA core sequences CACGTG and CATGTG (Fig. 1). This DNA binding appeared to be dimeric based on mixing experiments that result in the formation of a single intermediate mobility complex (Fig. 2). Although this observation does not formally prove $2: 1$ stoichiometry of protein to DNA, the DNA cocrystallographic analyses of Max and USF showed dimeric protein interaction with the cognate DNA template (Ferré-D'Amaré et al. 1993, 1994). Additionally, the importance of $\mathrm{Mi}^{\prime}$ 's leucine zipper was demonstrated by the loss of DNA binding upon its deletion. A substantial body of data indicate that the leucine zipper is necessary for dimerization and DNA binding by b-HLH-ZIP proteins (Dang et al. 1989; Gregor et al. 1990; Beckmann and Kadesch 1991; Blackwood and Eisenman 1991; Fisher et al. 1991; Prendergast et al. 1991; Blanar and Rutter 1992; Roman et al. 1992).

\section{Mi belongs to a discrete MiT family}

Based on the phenotypic complexity of heterozygous combinations of mi alleles (for review, see Green 1989), it is likely that mi function depends on heterodimer formation during development. Heterodimeric DNA binding was seen for Mi protein in combination with TFEB, TFE3, or TFEC (Fig. 2). With the observation that TFEB and TFEC were also capable of heterodimerization and DNA binding, all dimeric combinations of these factors have now been demonstrated (Fig. 2; Fisher et al. 1991; Zhao et al. 1993). Heteromeric DNA-binding interactions are otherwise quite restricted for these proteins, as none of them have been shown to heterodimerize with other HLH or HLH-ZIP factors. Whereas TFEB and TFE3 are ubiquitous factors (Beckmann et al. 1990; Carr and Sharp 1990) and TFEC is tissue restricted (Zhao et al. 
A
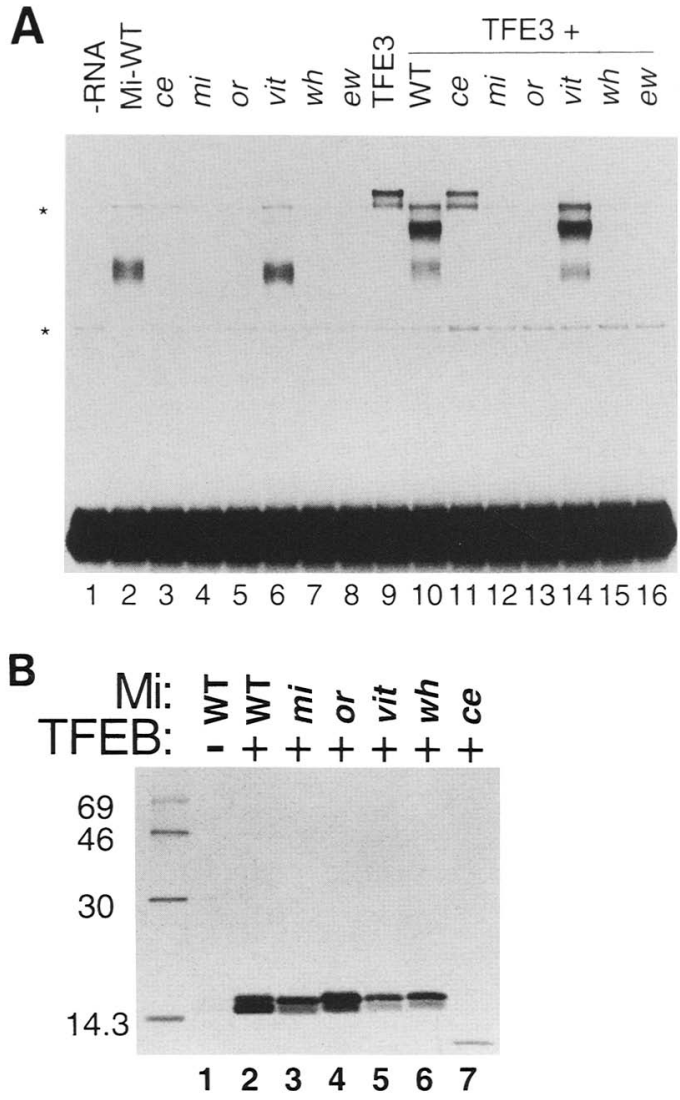

Figure 3. DNA-binding properties of mi mutants. (A) Wildtype $\mathrm{Mi}(\mathrm{Mi}-\mathrm{WT})$ and six different mutant $\mathrm{Mi}$ proteins were synthesized in vitro as amino-terminal deletions beginning with amino acid 109 (to visualize intermediate mobility complexes). Proteins were tested in DNA-binding assays either alone (lanes 2-8) or in post-translational mixes with TFE3 (lanes 10-16). The semidominant alleles $m i, M i^{o r}, M i^{w h}$, and the recessive alleles $m i^{c e}, m i^{\text {vit }}$, and $m i^{\text {ew }}$ were tested. The positions of two background reticulocyte bands are indicated $\left({ }^{*}\right)$, the lower one being remote from the strong signals and demonstrating evenness of sample loading. (B) Immunoprecipitation of wild-type (WT) and mutant Mi proteins with unlabeled recombinant TFEB, using a TFEB specific antibody. Specificity is seen in lane 1, where lack of TFEB results in no coprecipitation. Wild-type $\mathrm{Mi}$, the three dominant-negative proteins $\left(\mathrm{mi}, \mathrm{Mi}^{\text {or }}\right.$, and $\mathrm{Mi}^{\text {wh }}$, and $\mathrm{mi}^{\text {vit }}$ coprecipitate efficiently with TFEB (lanes 2-6); mice, a zipperless protein, is very weakly coprecipitated, perhaps through a propensity to form HLH-dependent tetramers (lane 7).

1993), it will be important to determine the developmental expression of these factors within cell lineages affected by mi mutations. Thus, these four proteins represent a distinct MiT family that likely participates in pivotal developmental pathways, although other family members might exist as well.

\section{Biochemical lesions and biological consequences}

We show here that dominant-negative protein behavior appears to explain semidominant inheritance of $\mathrm{mi}$ alleles. This is relevant for mouse $m i$ and is likely to be important in the human pigmentation disorder Waardenburg Syndrome, which is dominantly inherited and was recently linked to the human mi locus (Hughes et al. 1994). The behavior of these mutants, particularly those with unanticipated protein function, may aid in the
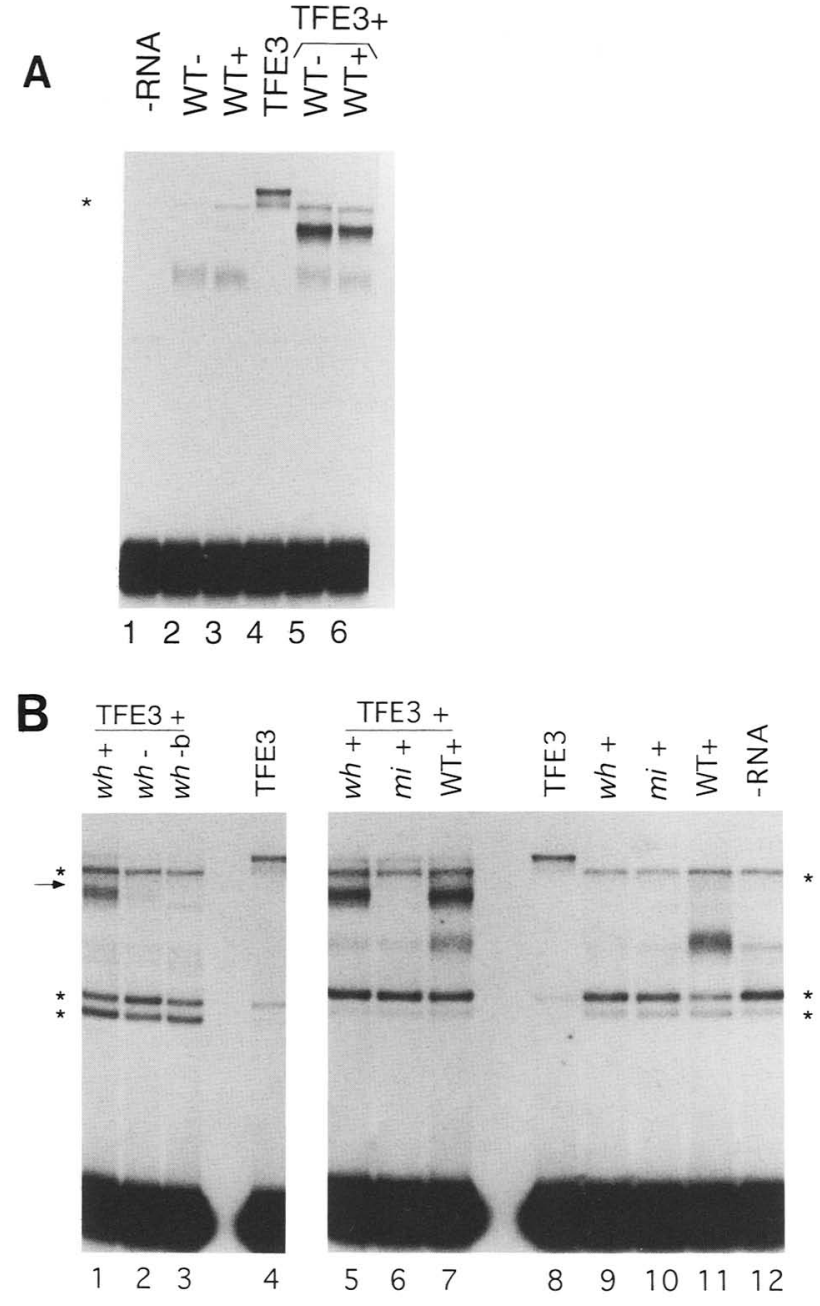

Figure 4. Alternative splice restores heteromeric DNA binding by $\mathrm{Mi}^{\mathrm{wh}}$. (A) DNA binding by two splice forms of Mi. Wild-type Mi protein $(\mathrm{A} \Delta 109 ; \mathrm{C} \Delta 308)$ either lacking (WT - ) or containing $(\mathrm{WT}+)$ the 6-amino-acid alternative exon was tested for DNA binding using the CACGTG probe, either alone or in the presence of TFE3. No obvious differences in DNA binding or heterodimerization were apparent. Several background bands $\left(^{\star}\right)$ represent reticulocyte proteins capable of DNA binding. (B) Sixamino-acid insert restores heterodimeric DNA binding by $\mathrm{Mi}^{\mathrm{wh}}$. The basic domain mutant $\mathrm{Mi}^{\mathrm{wh}}(\mathrm{A} \Delta 109$; C $\Delta 308$ ) was synthesized either with (Wh + ) or without (Wh - ) the 6-amino-acid insert and tested for DNA binding (CACGTG) in the presence of TFE3 (lanes 1-8) or alone (lane 9). A truncated form of $M i^{\text {wh }}$ contains only the b-HLH-ZIP (Wh-b). Another basic domain mutant, mi, was also synthesized from amino acid 109 $(\mathrm{A} \Delta 109 ; \mathrm{C} \Delta 308)$ in the presence ( $\mathrm{mi}+$ ) or absence (see Fig. 3) of the 6-amino-acid insert and tested for DNA binding with TFE3 (lane 6) or alone (lane 10). Presence of the 6 amino acids restored heterodimeric DNA binding to the $\mathrm{Mi}^{\mathrm{wh}}$ mutant $(\rightarrow \mid$ without affecting the mi protein. Several background reticulocyte lysate bands are observed (see lane 12, unprogrammed lysate). 


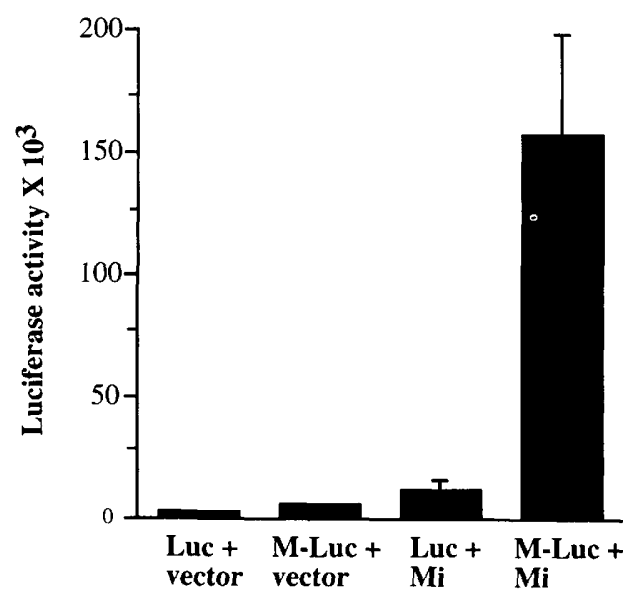

Figure 5. Mi stimulates transcription from a promoter construct containing $M$-box elements. NIH-3T3 cells were transiently transfected and assayed after $24 \mathrm{hr}$ for luciferase activity (expressed in relative light units). Error bars represent the standard deviation of triplicate samples. Transfected DNA contained a luciferase reporter plasmid containing a minimal SV40 promoter alone (Luc) or carrying four upstream copies of an M-box element (M-Luc), and a CMV-driven expression vector alone (vector) or containing a cDNA encoding wild-type Mi (Mi) lacking the 6-amino-acid alternative insert. Weak $M$ box-specific basal activity is seen in $3 \mathrm{~T} 3$ cells as well as strong Mispecific trans-activation.

identification and characterization of human mi lesions capable of producing Waardenburg Syndrome, eventually allowing for genetic screening in affected families. DNA recognition by the basic domain can be disrupted in several ways, some of which are reminiscent of the MyoD inhibitor Id (Benezra et al. 1990) and the Drosophila factor extramacrochaete (Ellis et al. 1990; Garrel and Modolell 1990).

The basic domain of b-HLH-ZIP proteins recognizes DNA through a discrete $\alpha$-helical face (Fisher et al. 1991) that forms an uninterrupted structure with helix 1 of the HLH domain (Ferré-D'Amaré et al. 1993). This is an intrinsically unstable $\alpha$-helix requiring DNA binding to stabilize its folding (Fisher et al. 1993; Ferré-D'Amaré et al. 1994). The mi protein lacks a basic region arginine (Hodgkinson et al. 1993) which should shift the rotational register of the basic domain $\alpha$ helix by $\sim 100^{\circ}$ relative to the $\mathrm{HLH}$, precluding DNA binding. The R215K mutation in $\mathrm{Mi}^{\text {or }}$ (Steingrímsson et al. 1994) destroys DNA binding in TFEB (Fisher et al. 1993) as well as in Mi (Fig. 3). Although this position appeared to only make a phosphate contact in the cocrystal structure of Max/ DNA (Ferré-D'Amaré et al. 1993), the fact that lysine could not substitute suggests another critical function, most likely including salt bridge formation with the upstream glutamate, thereby stabilizing $\alpha$-helical folding. Surprisingly the semidominant mutation $\mathrm{I} 212 \mathrm{~N}\left(\mathrm{Mi}^{\mathrm{wh}}\right)$ is predicted to face away from the major groove of the DNA on the basic domain $\alpha$-helix (Fisher et al. 1991, 1993; Ferré-D'Amaré et al. 1993) and provides evidence that the basic domain is subject to significant regulatory interactions (see below).
Mi proteins producing recessive inheritance are also instructive regarding b-HLH-ZIP function and highlight functionally relevant regions unlikely to produce the dominant inheritance of Waardenburg Syndrome. Importantly, two $\left(\mathrm{mi}^{\mathrm{vit}}\right.$ and $\left.\mathrm{mi}^{\mathrm{ew}}\right)$ of the three display biochemical behavior that is not expected. The third, mice, introduces a stop codon at the carboxyl terminus of the HLH domain (Steingrímsson et al. 1994), thereby truncating the leucine zipper. The transcription factor USF, however, appears to be capable of binding DNA without its leucine zipper (Gregor et al. 1990; Ferré-D'Amaré et al. 1994). By failing to dimerize, the $\mathrm{mi}^{\mathrm{ce}}$ protein should exert no dominant-negative effect at the level of DNA binding, as was observed in mixing experiments (Fig. 3). The weak coimmunoprecipitation of $\mathrm{mi}^{\mathrm{ce}}$ by TFEB (Fig. 4) suggests that the HLH domain alone can measurably oligomerize, perhaps as a tetramer, in the absence of DNA (Anthony-Cahill et al. 1992; Farmer et al. 1992; Fairman et al. 1993; Fisher et al. 1993).

The $\mathrm{mi}^{\mathrm{ew}}$ allele predicts a 25 -amino-acid deletion (Steingrímsson et al. 1994) that begins amino-terminal to (and deletes much of) the basic domain. This protein failed to bind DNA as either a homodimer or heterodimer. Like the semidominant alleles, it repressed DNA binding by wild-type protein because the HLH-ZIP domains were intact. Interestingly, the $\mathrm{mi}^{\mathrm{ew}}$ allele is inherited recessively suggesting that dominant-negative function is not fully realized in vivo. Potential explanations include the loss of a nuclear localization signal or decrease in protein stability.

The D222N mutations $\left(\mathrm{mi}^{\text {vit }}\right)$ produces a helix $1 \mathrm{mu}$ tation (Steingrimsson et al. 1994) with virtually no measurable effect on DNA binding (Fig. 3) but produces progressive, aging-dependent melanocyte death (Lerner 1986; Lerner et al. 1986). It is possible that the small $(6 \%)$ difference in $K_{\mathrm{d}}$ produced by this mutation is sufficient to produce the aging-dependent vitiligo in these mice. Alternatively, this helix 1 mutation may affect tetramerization, a property of many HLH proteins. TFEB has been shown previously to exist in a tetrameric state in solution that dissociates into DNA-binding dimers upon addition of DNA (Fisher et al. 1991). Similar tetramers have been observed for several other HLH-containing proteins including Myc (Dang et al. 1989), MyoD (Anthony-Cahill et al. 1992), and myogenin (Farmer et al. 1992). The Id protein's inhibition of MyoD DNA binding appears to be mediated by tetrameric complexes (Fairman et al. 1993/ consistent with the observation that tetrameric forms cannot bind DNA (Fisher et al. 1991). The aspartate 222 mutated in $\mathrm{mi}^{\text {vit }}$ (Steingrímsson et al. 1994) is located within the four-helix bundle predicted from the Max/DNA cocrystal structure (Ferré-D'Amaré et al. 1993) and could participate in interhelical salt bridges, although its disruption does not appreciably affect dimerization.

\section{Alternative splice modulates DNA binding}

Although b-HLH-ZIP DNA binding is generally thought to occur independently of major influences outside this 
domain, we observed here a noteworthy effect on DNA binding by the presence or absence of the 6-amino-acid alternative insert (Hodgkinson et al. 1993) upstream of the basic region. Wild-type protein shows only a modestly $(20 \%)$ enhanced DNA affinity in the presence of this insert, but a basic domain mutation (I212N, the $M i^{\text {wh }}$ mutation; Steingrimsson et al. 1994) could be strikingly rescued for heterodimeric DNA binding by the insert (Fig. 4). This observation suggests that the b-HLH-ZIP, and more specifically the I212 site in the basic region, are subject to functionally important intramolecular interactions, an observation that may extend to other b-HLH(-ZIP) factors. The location of the 6-amino-acid insert, amino-terminal to the basic domain, corresponds to the site of a 9-amino-acid alternatively spliced insert in Max (Blackwood and Eisenman 1991). Kinetic data suggest that Max has a slower off rate and altered affinity in the presence of its 9-amino-acid insert (Bousset et al. 1993; Kretzner et al. 1993). Virtually all b-HLH-ZIP proteins contain consensus casein kinase II sites at this same location (see Fisher et al. 1993, and references therein). Phosphorylation appears to alter Max DNA binding in the direction of lower affinity (Berberich and Cole 1992; Bousset et al. 1993), resulting in preferential heterodimeric DNA binding with Myc. The presence and configuration of negatively charged moieties near the basic domain may influence protein-DNA stability through repulsive forces with the DNA backbone. Similar influences of acidic residues upstream of the basic domain of E12 significantly suppress homodimeric DNA binding in this b-HLH factor (Sun and Baltimore 1991), suggesting that comparable mechanisms operate in other basic domain-containing transcription factors. The $b-\mathrm{HLH}-\mathrm{ZIP}$ protein USF contains a direct repeat peptide sequence that resembles an immunoglobulin hinge motif (Gregor et al. 1990). The presence of proline near the amino terminus of all b-HLHZIP basic domains suggests that the peptide backbone is kinked in such a fashion that the upstream amino acids may reach back in the vicinity of the basic domain. It is also interesting that the $\mathrm{I} 212$ mutation (Steingrímsson et al. 1994) occurs on the solvent exposed surface of the basic domain. Although this position is not likely to contact DNA (Fisher et al. 1993; Ferré-D'Amaré 1993; Steingrímsson et al. 1994), it is strikingly conserved as a hydrophobic residue in all CACGTG-binding b- $\mathrm{HLH}-$ ZIP proteins and is usually an arginine in CAGCTG binding ones (Dang et al. 1992). Because the b-HLH-ZIP basic domain is an intrinsically unstable $\alpha$-helix (Fisher et al. 1993; Ferré-D'Amaré et al. 1994), interactions on this other face may affect DNA binding by influencing $\alpha$-helical folding. Although the mechanism by which the upstream region influences DNA binding remains unclear, it is likely to be functionally important because of its biological consequences in mice carrying the $m i^{s p}$ or $M i^{w h}$ mutations. The mild "enhancing" phenotype of $\mathrm{mi}^{\mathrm{sp}}$ lacking the insert (Wolfe and Coleman 1964) and the interallelic complementation of $\mathrm{Mi}^{\text {wh }}$ (Grüneberg 1952; Hollander 1968; Konyukhov and Osipov 1968; Steingrimsson et al. 1994) might both be explained $\left(\mathrm{mi}^{\mathrm{sp}}\right.$ more straightforwardly| by this unique biochemistry, representing novel mechanisms for influencing genetic behavior.

\section{Mi activates the pigmentation gene $M$-box element}

One example of the biological activity of Mi was demonstrated by its ability to trans-activate a reporter element driven by the $M$ box (Fig. 5). This element contains $11 \mathrm{bp}$ that are perfectly conserved in the promoters of the three major pigmentation enzyme genes in both mouse and human and consists of $11 \mathrm{bp}$ with a hexamer core of CATGTG (Shibahara et al. 1991; Lowings et al. 1992; Yavuzer and Goding 1994). The immunoglobulin enhancer $\mu \mathrm{E} 3$ site contains the same core CATGTG and can be transcriptually activated by Mi (data not shown). It is attractive to speculate that through M-box recognition, Mi provides a melanocyte-specific signal that activates the pigmentation program, potentially qualifying it as a master gene for melanocyte development. Although the $\mathrm{M}$ box can be bound by different b-HLH-ZIP proteins such as USF (Yavuzer and Goding 1994), Mi's transactivation motif(s) might provide melanocyte-specific signals. This idea is consistent with the observation that the $M$ box is a melanocyte-specific enhancer element only when it is linked to the TATA box of a pigmentation gene promoter (Lowings et al. 1992). Therefore, even if bound at an M-box site, different activator domains might not function like that of Mi. Importantly, whereas $\mathrm{Mi}$ is expressed in a few tissues other than pigment cells, the alternative splice form in melanocytes appears to be unique (Hodgkinson et al. 1993) and may represent a truly melanocyte-specific b-HLH-ZIP factor. It will be important to examine MiT family expression in cells affected by mi mutations. Two of Mi's dimerization partners have been shown to encode transcriptional inhibitory activity. TFEC represses TFE3-dependent transcription (Zhao et al. 1993) and an alternative splice form of TFE3 has also been shown to repress the longer transcriptionally active form of TFE3 (Beckmann et al. 1990; Roman et al. 1991). Thus, regulated MiT protein dimers might direct the tissue-specific expression of pigmentation program genes.

$\mathrm{Mi}$ also functions in melanocytes as a lineage-restricted survival factor. During melanocyte develoment, cells harboring mi mutations appear to die, rather than (e.g.) survive without producing pigment. The prospect that pigmentation enzymes and melanocyte survival genes are downstream effectors of $\mathrm{Mi}$ represents one of very few known transcription factor targets for the b-HLH-ZIP family. An understanding of the role of $\mathrm{Mi}$ in melanocyte development may provide insight into pathways of cellular proliferation and death in which other b-HLH-ZIP proteins, like Myc/Max, are known to play roles.

\section{Materials and methods}

\section{DNA clones}

The wild-type mi cDNA derived from melan-c cells was ex- 
pressed in vitro from the clone $\mathrm{pBS}-\mathrm{Mi}$, which contains the cDNA inserted into the EcoRI site of pBluescript SK -. This cDNA lacks the 6-amino-acid alternative exon. Mutants corresponding to the alleles $\mathrm{mi}$ (del 775-777), $\mathrm{Mi}^{\text {or }}(\mathrm{G} 776 \mathrm{~A}), \mathrm{Mi}^{\text {wh }}$ (T764A), and the recessive alleles $\mathrm{mi}^{\text {ce }}(\mathrm{C} 916 \mathrm{~T})$, and $\mathrm{mi}^{\text {vit }}$ (G793A) (Steingrímsson et al. 1994) were generated by site-directed mutagenesis of pBS-Mi using the method of Eckstein according to the recommendations of the manufacturer (Amersham). Templates for $m i^{e w}$, and constructs containing the 6-amino-acid alternative exon were expressed from PCR-derived fragments made from wild-type as well as $m i$ and $M i^{\text {wh }}$ mutant tissues. Expression templates were verified by DNA sequencing. TFEB was expressed from clone pTFEB-A $\Delta 265$ (Fisher et al. 1991). TFE3 in vitro expression vector was provided by Dr. T. Kadesch (Beckman et al. 1990). TFEC expression vector was provided by Dr. B. de Crombrugghe (Zhao et al. 1993). E47S was expressed from the plasmid pE47S (Mürre et al. 1989). His fusion $\mathrm{Mi}$ was expressed from a plasmid containing the BamHI-BamHI insert fragment from pBS-Mi inserted into the BamHI site of pET 15b (Novagen). For mammalian expression of $\mathrm{Mi}$, the cDNA was cloned into the HindIII and $\mathrm{XbaI}$ sites of pRC-CMV (InVitrogen). The luciferase reporter plasmid was made by cloning an oligonucleotide containing four tandem repeats of the M box (AGTCATGTGCT) into the KpnI-XhoI sites of the luciferase reporter plasmid pGL2 promoter (Promega).

\section{Protein expression}

In vitro-translated proteins were made in rabbit reticulocyte lysate (Promega) using RNA from in vitro transcription using T7 RNA polymerase according to the manufacturer's recommendations (Pharmacia) for $\mathrm{pBS}-\mathrm{Mi}$ and the corresponding $\mathrm{mi}$, $M i^{w h}, M i^{o r}, m i^{\text {vit }}$, and $\mathrm{mi}^{\text {ie }}$ mutants as well as TFE3. Full-length Mi proteins were obtained by linearizing with $S m a I$, and carboxy-terminal deletions at amino acids 319 and 261 were obtained by linearizing with $\mathrm{XmnI}$ and $A v a I I$, respectively. TFEB and E47S were transcribed using T3 RNA polymerase (Fisher et al. 1991) (Pharmacia). Amino-terminal deletions and the DNAbinding domain of TFEC were made by amplifying discrete fragments using $5^{\prime}$ primers that begin at the described residue and append an initiation ATG, Kozak sequence, and T3 RNA polymerase promoter (derived from the plasmid pBS-ATG, (Baldwin et al. 1990) followed by transcription and translation in vitro. In vitro-translated proteins were quantitated by TCA precipitation and SDS-PAGE and equivalent quantities were added to gel shift assays. Recombinant TFEB was synthesized as described (Fisher et al. 1993). Recombinant His fusion Mi protein was synthesized in the bacterial strain BL-21, purified using nickel chelate chromatography (Qiagen), and eluted with $100 \mathrm{~mm}$ imidazole.

\section{Electrophoretic mobility shift assay, affinity measurements, and immunoprecipitation}

DNA-binding assays were performed as described (Fisher et al. 1993 ) in $20-\mu \mathrm{l}$ reactions containing $5 \%$ glycerol, $100 \mathrm{~mm} \mathrm{KCl}$, $10 \mathrm{~mm}$ Tris (pH 7.4), $1 \mathrm{~mm} \mathrm{DTT}$, and $\sim 5 \times 10^{4} \mathrm{cpm}$ of ${ }^{32} \mathrm{P}$-endlabeled probe DNA. In mixing experiments, separately translated proteins were incubated at $37^{\circ} \mathrm{C}$ for $30 \mathrm{~min}$ prior to the addition of probe DNA. CACGTG, CATGTG, and double point mutant probes were used as described (Fisher et al. 1991). Polyacrylamide gels $(6 \%$ Tris-glycine-EDTA $)$ were run and subjected to autoradiography after drying. Competitors were prepared as described previously (Fisher et al. 1991). Reactions probed with the CACGTG probe contained $1 \mu \mathrm{g}$ of poly[d(I-C)] per 20- $\mu$ l reaction, whereas those containing CATGTG probe contained $0.5 \mu \mathrm{g}$. $K_{\mathrm{d}}$ was determined by calculating half satu- ration from the initial (linear) slope of protein titrations under conditions of probe excess. Proteins were derived from in vitro translation reactions and were quantitated by determining probe saturation in gel shift using probe of known specific activity. Mi will aggregate with DNA in the absence of poly[d(IC)]; therefore this nonspecific competitor was added to all reactions (as above). $K_{\mathrm{d}}$ measurements therefore reflect its presence. Equilibrium conditions were established by incubation at $30^{\circ} \mathrm{C}$ for $75 \mathrm{~min}$. Quantitation was carried out using a PhosphorImager (Molecular Dynamics). Immunoprecipitations were performed by mixing the various proteins under gel shift conditions (excluding poly [d(I-C)] and DNA probe) at $37^{\circ} \mathrm{C}$ for $1 \mathrm{hr}$, followed by addition of $3 \mu \mathrm{l}$ of rabbit anti-TFEB antiserum and freshly washed protein A-Sepharose (Pharmacia), incubation at $4^{\circ} \mathrm{C}$ for $2 \mathrm{hr}$, and three washes with PBS containing $0.1 \%$ NP-40 prior to elution in loading buffer and SDS-PAGE.

\section{Transient transfections and luciferase assay}

NIH-3T3 cells were maintained in Dulbecco's modified Eagle medium supplemented with $5 \%$ calf serum $/ 5 \%$ fetal calf serum, $4 \mathrm{~mm} \mathrm{~L}$-glutamine, $100 \mathrm{U} / \mathrm{ml}$ of penicillin, and $100 \mu \mathrm{g} / \mathrm{ml}$ of streptomycin (GIBCO BRL). Cells were split 24-36 hr prior to transfection such that cells were $\sim 60 \%$ confluent at the time of DNA addition, and were refed with fresh medium $8 \mathrm{hr}$ prior to transfection. Transfections were carried out by calcium phosphate/DNA coprecipitation according to Kingston (1993) and harvested after $24 \mathrm{hr}$. Three 6-cm plates were each transfected with $0.25 \mu \mathrm{g}$ of luciferase reporter plasmid, $1 \mu \mathrm{g}$ of $\beta$-galactosidase control plasmid pRSV- $\beta$-Gal (Edlund et al. 1985), $4.7 \mu \mathrm{g}$ of cytomegalovirus (CMV)-driven expression vector $\mathrm{pRC}-\mathrm{CMV}$ (Invitrogen), and $4.05 \mu \mathrm{g}$ of carrier DNA pBS-SK (Stratagene).

At harvest, plates were washed once with phosphate-buffered saline, lysed, and analyzed using a Monolight 2010 Luminometer according to the recommendations of the manufacturer (Analytical Luminescence Laboratory, San Diego, CA). $\beta$-Galactosidase activity in cell lysates as a measure of relative transfection efficiency was used to adjust luciferase data and was assayed as described (Sambrook et al. 1989).

\section{Acknowledgments}

We wish to thank Dr. Phillip Sharp for encouragement and support, Dr. Karen J. Moore for useful discussions, and Drs. T. Kadesch, B. deCrombrugghe and C. Mürre for plasmids. This work was supported in part by a grant from the Fundacion Internacional Jose Carreras, and the National Cancer Institute under contract N01-CO-74101 with ABL.

The publication costs of this article were defrayed in part by payment of page charges. This article must therefore be hereby marked "advertisement" in accordance with 18 USC section 1734 solely to indicate this fact.

\section{References}

Amati, B., M.W. Brooks, N. Levy, T.D. Littlewood, G.I. Evan, and $H$. Land. 1993. Oncogenic activity of the c-Myc protein requires dimerization with Max. Cell 72: 233-245.

Anthony-Cahill, S.J., P.A. Benfield, R. Fairman, Z.R. Wasserman, S.L. Brenner, W.F. Stafford, C. Altenbach, W.L. Hubbell, and W.F. DeGrado. 1992. Molecular characterization of helix-loop-helix peptides. Science 255: 979-983.

Ayer, B. and R.N. Eisenman. 1993. A switch from Myc:Max to Mad:Max heterocomplexes accompanies monocyte/macrophage differentiation. Genes \& Dev. 7: 2110-2119. 
Baldwin, A.S., K.P. LeClair, H. Singh, and P.A. Sharp. 1990. A large protein containing zinc finger domains binds to related sequence elements in the enhancers of the class I major histocompatibility complex. Mol. Cell. Biol. 10: 1406-1414.

Beckmann, H.L. and T. Kadesch. 1991. The leucine zipper of TFE3 dictates helix-loop-helix dimerization specificity. Genes \& Dev. 5: 1057-1066.

Beckmann, H.L., L.K. Su, and T. Kadesch. 1990. TFE3: A helixloop-helix protein that activates transcription through the immunoglobulin enhancer $\mu \mathrm{E} 3$ motif. Genes \& Dev. 4: 167179.

Benezra, R., R.L. Davis, D. Lockshon, D.L. Turner, and H. Weintraub. 1990. The protein Id: A negative regulator of helixloop-helix DNA binding proteins. Cell 61: 49-59.

Berberich, S.J. and M.D. Cole. 1992. Casein kinase II inhibits the DNA-binding activity of Max homodimers but not Myc/ Max heterodimers. Genes \& Dev. 6: 166-176.

Blackwood, E.M. and R.N. Eisenman. 1991. Max: A helix-loophelix zipper protein that forms a sequence-specific DNAbinding complex with Myc. Science 251: 1211-1217.

Blanar, M.A. and W.J. Rutter. 1992. Interaction cloning: Identification of a helix-loop-helix zipper protein that interacts with c-Fox. Science 256: 1014-1018.

Bousset, K., M. Henriksson, J.M. Luxcher-Firzlaff, D.W. Litchfield, and B. Lüscher. 1993. Identification of casein kinase II phosphorylation sites in Max: Effects on DNA-binding kinetics of Max homo- and Myc? Max heterodimers. Oncogene 8: 3211-3220.

Carr, C.S. and P.A. Sharp. 1990. A helix-loop-helix protein related to immunoglobulin E box-binding proteins. Mol. Cell. Biol. 10: 4384-4388.

Dang, C.V., M. McGuire, M. Buckmire, and W.M.F. Lee. 1989. Involvement of the "leucine zipper" region in the oligomerization and transforming activity of human c-Myc protein. Nature 337: 664-666.

Dang, C.V., C. Dolde, M.C. Gillison, and G.J. Kato. 1992. Discrimination between related DNA sites by a single amino acid residue of Myc-related basic-helix-loop-helix proteins. Proc. Natl. Acad. Sci. 89: 559-602.

Dubreuil, P., L. Forrester, R. Rottapel, M. Reedijk, J. Fujita, and A. Bernstein. 1991. The c-fms gene complements the mitogenic defect in mast cells derived from mutant $\mathrm{W}$ mice but not $\mathrm{mi}$ (microphthalmia) mice. Proc. Natl. Acad. Sci. 88: 2341-2345.

Ebi, Y., Y. Kanakura, T. Jippo-Kanemoto, T. Tsujimura, T. Furitsu, H. Ikeda, S. Adachi, T. Kasugai, S. Nomura, Y. Kanayama, A. Yamatodani, S. Nishikawa, Y. Matsuzawa, and Y. Kitamura. 1992. Low c-kit expression of cultured mast cells of $\mathrm{mi} / \mathrm{mi}$ genotype may be involved in their defective responses to fibroblasts that express the ligand for c-kit. Blood 80: 1454-1462.

Edlund, T., M.D. Walker, P.J. Barr, and W.J. Rutter. 1985. Cellspecific expression of the rat insulin gene: Evidence for role of two distinct 5' flanking elements. Science 230: 912-916.

Ellis, H.M., D.R. Spann, and J.R. Posakony. 1990. extramacrochaete, a negative regulator of sensory organ development in Drosophila, defines a new class of helix-loop-helix proteins. Cell 61: 27-38.

Fairman, R., R.K. Beran-Steed, S.J. Anthony-Cahill, J.D. Lear, W.F. Stafford, W.F. DeGrado, P.A. Benfield, and S.L. Brenner. 1993. Multiple oligomeric states regulate the DNA binding of helix-loop-helix peptides. Proc. Natl. Acad. Sci. 90: 10429-10433.

Farmer, K., F. Catala, and W.E. Wright. 1992. Alternative multimeric structures affect myogenin DNA binding activity. $J$. Biol. Chem. 267: 5631-5636.
Ferré-D'Amaré, A.R., G.C. Prendergast, E.B. Ziff, and S.K. Burley. 1993. Recognition by Max of its cognate DNA through a dimeric b/HLH/Z domain. Nature 363: 38-45.

Ferré-D'Amaré, A.R., P. Pognonec, R.G. Roeder, and S.K. Burley. 1994. Structure and function of the $\mathrm{b} / \mathrm{HLH} / \mathrm{Z}$ domain of USF. EMBO \%. 13: 180-189.

Fisher, D.E., C.S. Carr, L.A. Parent, and P.A. Sharp. 1991. TFEB has DNA-binding and oligomerization properties of a unique helix-loop-helix/leucine zipper family. Genes \& Dev. 5: 2342-2352.

Fisher, D.E., L.A. Parent, and P.A. Sharp. 1993. High affinity DNA-binding Myc analogs: Recognition by an $\alpha$ helix. Cell 72: $467-476$.

Garrel, J. and J. Modolell. 1990. The Drosophila extramacrochaetae locus, an antagonist of proneural genes that, like these genes, encodes a helix-loop-helix protein. Cell 61: 39-48.

Green, M.C. 1989. Catalog of mutant genes and polymorphic loci. Genetic variants and strains of the laboratory mouse. Oxford University Press. Oxford, UK.

Gregor, P.D., M. Sawadogo, and R.G. Roeder. 1990. The adenovirus major late transcription factor USF is a member of the helix-loop-helix group of regulatory proteins and binds to DNA as a dimer. Genes \& Dev. 4: 1730-1740.

Grüneberg, H. 1952. The genetics of the mouse. Martinus Nijhoff, The Hague, Netherlands.

Halaban, R. and G. Moellmann. 1993. White mutants in mice shedding light on humans. I. Invest. Dermatol. 100: 176S$185 \mathrm{~S}$.

Hertwig, P. 1942. Neue mutationen und kopplungsgruppen bei der hausmaus. Z. Indukt. Abstammungs-Vererbungsl. 80: 220-246.

Hodgkinson, C.A., K.J. Moore, A. Nakayama, E. Steingrímsson, N.G. Copeland, N.A. Jenkins, and H. Arnheiter. 1993. Mutations at the mouse microphthalmia locus are associated with defects in a gene encoding a novel basic-helix-loophelix-zipper protein. Cell 74: 395-404.

Hollander, W.F. 1968. Complementary alleles at the mi-locus in the mouse. Genetics 60: 189.

Hu, Y.-F., B. Leuscher, A. Admon, N. Mermod, and R. Tijan. 1990. Transcription factor AP-4 contains multiple dimerization domains that regulate dimer specificity. Genes \& Dev. 4: 1741-1752.

Hughes, A.E., V.E. Newton, X.Z. Liu, and A.P. Read. 1994. A gene for Waardenburg Syndrome type 2 maps close to the human homologue of the microphthalmia gene at chromosome 3p12-p14.1. Nature Genet. 7: 509-512.

Hughes, J.J., J.B. Lingrel, J.M. Krakowsky, and K.P. Anderson. 1993. A helix-loop-helix transcription factor-like gene is located at the mi locus. J. Biol. Chem. 268: 20687-20690.

Kato, G.J., W.M.F. Lee, I. Chen, and C.W. Dang. 1992. Max: Functional domains and interaction with c-Myc. Genes \& Dev. 6: 81-92.

Kingston, R.E. 1993. Transfection of DNA into eukaryotic cells. In Current protocols in molecular biology. Wiley Interscience/Greene, New York.

Konyukhov, B.A. and V.V. Osipov. 1968. Interallelic complementation of microphthalmia and white genes in mice. Gentika 4: 65-76.

Kretzner, L., E.M. Blackwood, J. Mac, and R.N. Eisenmann. 1993. Transcriptional repression by Max proteins $\mathrm{p} 21$ and p22. The negative regulation of hematopoiesis. Cologne INSERM/John Libbey Eurotext, Cologne, Germany.

Lerner, A.B. 1986. Designation of a provisional gene symbol for a new mouse mutant. Mouse News Lett. 74: 125.

Lerner, A.B., T. Shiohara, R.E. Boissy, K.A. Jacobson, M.L. Lamoreux, and G.E. Moellmann. 1986. A mouse model for viti- 
ligo. J. Invest. Dermatol. 87: 299-304.

Lowings, P., U. Yavuzer, and C.R. Goding. 1992. Positive and negative elements regulate a melanocyte-specific promoter. Mol. Cell. Biol. 12: 3653-3662.

Mürre, C., P.S. McCaw, and D. Baltimore. 1989. A new DNA binding and dimerization motif in immunoglobulin enhancer binding, daughter-less, MyoD, and Myc proteins. Cell 56: 777-783.

Olson, E.N. 1990. MyoD family: A paradigm for development? Genes \& Dev. 4: 1454-1461.

Prendergast, G.C. and E.G. Ziff. 1992. A new bind for Myc. Trends Genet. 8: 91-96.

Prendergast, G.C., D. Lawe, and E.G. Ziff. 1991. Association of Myn, the murine homolog of Max, with c-Myc stimulates methylation-sensitive DNA binding and ras cotransformation. Cell 65: 395-407.

Roman, C., L. Cohn, and K. Calame. 1991. Creation of a transdominant negative form of transcription activator mRFE3 by differential splicing. Science 254: 94-97.

Roman, C., A.G. Matera, C. Cooper, S. Artandi, S. Blain, D.C. Ward, and K. Calame. 1992. mTFE3, an X-linked transcriptional activator containing basic helix-loop-helix and zipper domains, utilizes the zipper to stabilize both DNA binding and multimerization. Mol. Cell. Biol. 12: 817-827.

Sambrook, J., E.F. Fritsch, and T. Maniatis. 1989. Molecular cloning: A laboratory manual. Cold Spring Harbor Laboratory. Cold Spring Harbor, New York.

Shibahara, S., H. Taguchi, R.M. Muller, K. Shibata, T. Cohen, Y. Tomita, and H. Tagami. 1991. Structural organization of the pigment cell-specific gene located at the brown locus in mouse. J. Biol. Chem. 266: 15895-15901.

Steingrímsson, E., K.J. Moore, M.L. Lamoreux, A.R. FerréD'Amaré, S.K. Burley, D.C. Sanders-Zimring, L.C. Skow, C.A. Hodgkinson, H. Amheiter, N.G. Copeland, and N.A. Jenkins. 1994. Molecular genetic dissection of the bHLH-Zip protein encoded by the mouse microphthalmia locus. $\mathrm{Na}$ ture Genet. (in press).

Sun, X.H. and D. Baltimore. 1991. An inhibitory domain of E12 transcription factor prevents DNA binding in E12 homodimers but not in E12 heterodimers. Cell 64: 459-470.

Tachibana, M., L.A. Perez-Jurado, A. Nakayama, C.A. Hodgkinson, X. Li, M. Schneider, T. Miki, J. Fex, U. Francke, and H. Arnheiter. 1994. Cloning of MITF, the human homolog of the mouse microphthalmia gene, and assignment to human chromosome 3, region pl4.1-p12.3. Hum. Mol. Genet. 3: $553-557$.

Weintraub, H. 1994. The MyoD family and myogenesis: Redundancy, networks, and thresholds. Cell 75: 1241-1244.

Wolfe, H.G. and D.L. Coleman. 1964. Mi-spotted: A mutation in the mouse. Genet. Res. Camb. 5: 432-440.

Yavuzer, U. and C.R. Goding. 1994. Melanocyte-specific gene expression: Role of repression and identification of a melanocyte-specific factor, MSF. Mol. Cell. Biol. 14: 3494-3503.

Zervos, A.S. 1993. Mxil, a protein that specifically interacts with Max to bind Myc-Max recognition sites. Cell 72: 223 232.

Zhao, G.-Q., Q. Zhao, X. Shou, M.-G. Mattei, and B. DeCrombrugghe. 1993. TFEC, a basic helix-loop-helix protein, forms heterodimers with TFE3 and inhibits TFE3-dependent transcription activation. Mol. Cell. Biol. 13: 4505-4512. 


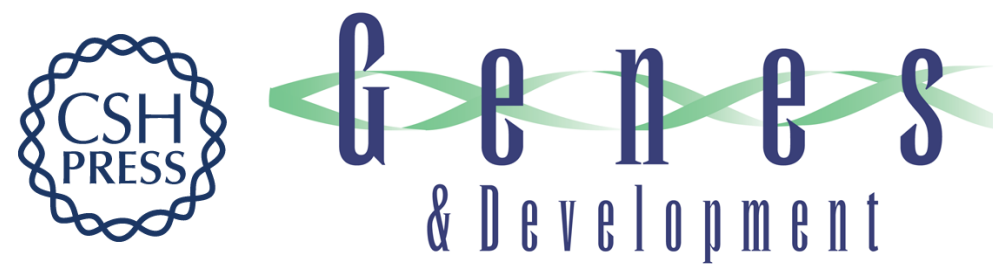

\section{microphthalmia, a critical factor in melanocyte development, defines a discrete transcription factor family.}

T J Hemesath, E Steingrímsson, G McGill, et al.

Genes Dev. 1994, 8:

Access the most recent version at doi:10.1101/gad.8.22.2770

References This article cites 52 articles, 27 of which can be accessed free at:

http://genesdev.cshlp.org/content/8/22/2770.full.html\#ref-list-1

License

Email Alerting

Service

Receive free email alerts when new articles cite this article - sign up in the box at the top right corner of the article or click here.

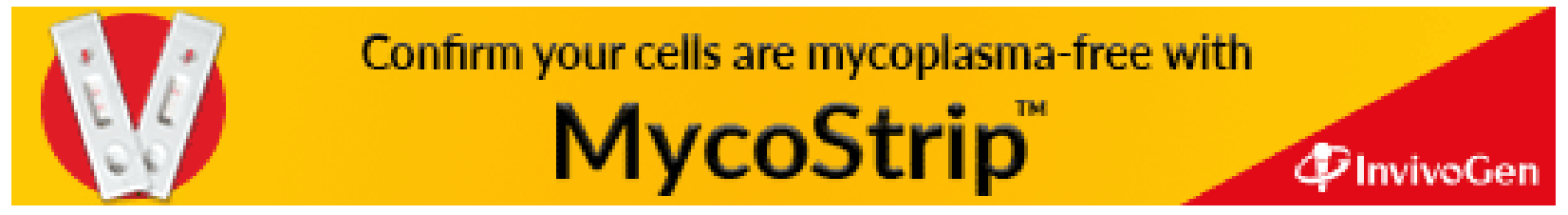

